\title{
Effect of metoprolol on chest pain in acute myocardial infarction
}

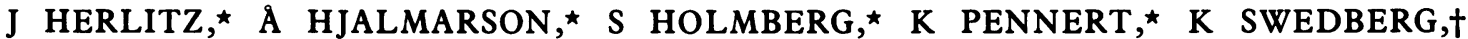

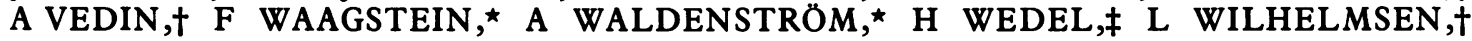 \\ C WILHELMSSON†
}

From the ${ }^{\star}$ Department of Medicine I, Sahlgren's Hospital; the †Department of Medicine, Östra Hospital; and the $\ddagger$ Nordic School of Public Health, Gothenburg, Sweden

SUMMARY A total of 1395 patients aged 40 to 74 years were included in a double blind trial with the beta $_{1}$ selective blocker metoprolol in suspected acute myocardial infarction. Metoprolol was given intravenously (15 mg) as soon as possible after admission to hospital followed by $200 \mathrm{mg}$ daily for three months. A placebo was given in the same manner. The severity of chest pain in the acute phase was calculated by recording the number of injections of analgesics given and the time from the start of blind treatment to the time when the last analgesic was given (duration of pain). The patients receiving metoprolol were given a lower mean number of injections of analgesics during the first four days and after randomisation than those receiving a placebo. The estimated duration of pain was shorter in the metoprolol group than in the placebo group. These effects were related to the initial heart rate, the initial systolic blood pressure, and the final site of the infarct as determined electrocardiographically. Thus metoprolol given in the acute phase of suspected or definite myocardial infarction appears to reduce the severity of chest pain.

Several studies have convincingly shown that beta blockade can relieve pain in angina pectoris. ${ }^{1-3}$ In a previous study, performed in Gothenburg, intravenous administration of beta receptor blocking agents shortly after the onset of a myocardial infarction resulted in the relief of chest pain. ${ }^{4}$ Similar results have since been reported by other groups. ${ }^{5-7}$ The number of patients included in these studies was small, and the treatment was given only to selected patients.

One of the secondary aims of the Gothenburg metoprolol trial was to evaluate the clinical course in the acute phase of myocardial infarction. The purpose of this study was to determine the effect of the beta selective blocker metoprolol on the need for analgesics and the estimated duration of pain in patients with a suspected or definite myocardial infarction.

Requests for reprints to Dr J Herlitz, Department of Medicine I, Sahlgren's Hospital, S-413 45 Göteborg, Sweden.

Accepted for publication 1 November 1983

\section{Patients and methods}

\section{STUDY POPULATION}

A detailed description of the study design and mortality at three months has been reported. ${ }^{8}$ A total of 1395 patients participated in the study. With few exceptions, all patients admitted to the three participating hospitals were evaluated for participation. The inclusion criteria were: (a) age range 40-74 years; (b) chest pain of acute onset and of $\geqslant 30 \mathrm{~min}$ duration or electrocardiographic signs of acute myocardial infarction with estimated onset of infarction within the previous $48 \mathrm{~h}$; and (c) residence in the catchment areas. The cardiovascular exclusion criteria were a heart rate $<45$ beats/min, a systolic blood pressure $<100 \mathrm{~mm} \mathrm{Hg}$, a $P R$ interval $\geqslant 0.24 \mathrm{~s}$, and signs of severe congestive heart failure (auscultatory pulmonary rales $>10 \mathrm{~cm}$ above the lung bases). There were some further exclusion criteria which have been reported elsewhere. ${ }^{8}$ Metoprolol $15 \mathrm{mg}$ was given intravenously ( $5 \mathrm{mg}$ as a rapid intravenous injection with two further doses at two minute intervals) as soon as possible after admission to hospital followed by $50 \mathrm{mg}$ orally four times a day (first tablet $15 \mathrm{~min}$ after the intravenous dose) for 
two days and thereafter $100 \mathrm{mg}$ twice daily for three months. A placebo was given in the same way. The treatment regimens were standardised and were the same at the three participating hospitals.

\section{CLASSIFICATION OF MYOCARDIAL INFARCTION}

The following criteria were used for the classification of definite and possible myocardial infarction. For definite myocardial infarction, two of the following three criteria had to be fulfilled: (a) chest pain of at least 15 minutes' duration; (b) $Q$ wave or ST segment elevation followed by $T$ wave inversion in at least two leads in a 12 lead standard electrocardiogram, and (c) two values for serum aspartate aminotransferase activity above the reference limit $(0.7 \mu \mathrm{kat} / \mathrm{l}(1 \mathrm{~kat}=1$ $\mathrm{mol} / \mathrm{s})$ ) in combination with lower or normal values for serum alanine aminotransferase activity. Electrocardiographic changes in only one lead or only one raised aspartate aminotransferase value in combination with at least one value for heat stable lactate dehydrogenase activity above a discriminatory border (4.3 $\mu \mathrm{kat} / \mathrm{l})$ were also regarded as evidence for definite myocardial infarction. Possible myocardial infarction was defined by the presence of chest pain together with one of the following criteria: (a) $\mathrm{T}$ wave inversion; (b) one raised value for aspartate aminotransferase in combination with lower or normal values for alanine aminotransferase; (c) one or more raised value for heat stable lactate dehydrogenase activity; and (d) $\mathrm{Q}$ wave or ST segment elevation followed by $\mathrm{T}$ wave inversion in only one lead.

\section{INFARCT SITE}

The patients with definite myocardial infarction were analysed for the site of infarct. The criteria for anterior myocardial infarction were the $Q$ wave appearance or ST-T wave changes in leads V1-V5 in a 12 lead standard electrocardiogram. The criteria for inferior myocardial infarction were: the criteria for definite myocardial infarction together with the $Q$ wave appearance or ST-T wave changes in leads II, III, or aVF. Patients with both anterior and inferior myocardial infarction, lateral myocardial infarction (electrocardiographic changes in leads I, aVL, V6, V7), and without electrocardiographic changes indicating myocardial infarction were classified as "other" myocardial infarction. Aspartate aminotransferase, alanine aminotransferase, and lactate dehydrogenase activity were determined according to the Scandinavian Committee on Enzymes. ${ }^{9}$ The heat labile isoenzymes of lactate dehydrogenase were inactivated according to Brydon and Smith. ${ }^{10}$

\section{NUMBER OF ANALGESIC INJECTIONS}

The-number of analgesic injections, consisting of morphine chloride $5 \mathrm{mg}$, pethidine chloride $50 \mathrm{mg}$, and pentazocine $30 \mathrm{mg}$, given during the first four days after randomisation was recorded. Morphine 5 $\mathrm{mg}$ intravenously or corresponding doses of other analgesics were given intermittently for the relief of pain. Guidelines specified in a manual of operation for the treatment of various complications meant that patients were routinely given $5 \mathrm{mg}$ morphine intravenously for pain and only in exceptional cases (intolerance to morphine) was pethidine or pentazocine given.

The number of analgesic injections was registered in 1310 patients (95\%). Information was missing in the remaining 85 patients (metoprolol 46 , placebo 39 ).

\section{DURATION OF PAIN}

The duration of pain was defined as the time from the start of double blind treatment to the time when the last analgesic dose was given. If the time interval between two doses exceeded 36 hours the duration of pain was estimated until the time when the first of these two injections was given. Duration of pain was calculated in 883 patients $(63 \%)$. Data were missing in 249 patients receiving metoprolol and in 263 receiving a placebo. The two main reasons for the missing data were: (a) when no analgesic was given after admission to the coronary care unit the information on the duration of pain was mostly inadequate; and (b) in several patients the time when analgesics were given was not known.

This study was planned before the metoprolol study started, and at that time the need for analgesics was chosen as a secondary endpoint. Time from the onset of pain and inclusion in the trial to the time when the last analgesic dose was given was chosen as a

Table 1 Mean delay $\pm S E M(h)$ from the onset of pain to the start of treatment in all patients and different subgroups.

\begin{tabular}{|c|c|c|c|}
\hline \multirow[t]{2}{*}{ Group } & \multicolumn{2}{|c|}{ Treatment group } & \multirow[b]{2}{*}{ Probability } \\
\hline & Placebo & Metoprolol & \\
\hline All patients & $11 \cdot 2 \pm 0 \cdot 4$ & $11 \cdot 1 \pm 0 \cdot 3$ & \\
\hline $\begin{array}{l}\text { Delay time } \\
\quad \leqslant 4 \mathrm{~h} \\
\leqslant 12 \mathrm{~h} \\
>12 \mathrm{~h} \\
\text { Initial heart rate }\end{array}$ & $\begin{array}{l}3 \cdot 2 \pm 0 \cdot 1 \\
6 \cdot 0 \pm 0 \cdot 1 \\
23 \cdot 7 \pm 0 \cdot 8\end{array}$ & $\begin{array}{l}3 \cdot 2 \pm 0 \cdot 1 \\
6 \cdot 0 \pm 0 \cdot 1 \\
21 \cdot 3 \pm 0 \cdot 6\end{array}$ & $0.011^{\star}$ \\
\hline $\begin{array}{l}<60 \text { beats } / \mathrm{min} \\
60-80 \text { beats } / \mathrm{min} \\
>80 \text { beats } / \mathrm{min}\end{array}$ & $\begin{array}{l}11 \cdot 0 \pm 0.8 \\
10 \cdot 7 \pm 0.5 \\
12 \cdot 7 \pm 1 \cdot 0\end{array}$ & $\begin{array}{l}10.5 \pm 0.8 \\
10.7 \pm 0.5 \\
12 \cdot 5 \pm 0.8\end{array}$ & \\
\hline $\begin{array}{l}\text { Initial systolic blood } \\
\text { pressure } \\
<120 \mathrm{~mm} \mathrm{Hg} \\
120-160 \mathrm{~mm} \mathrm{Hg} \\
>160 \mathrm{~mm} \mathrm{Hg}\end{array}$ & $\begin{array}{l}10.8 \pm 1 \cdot 0 \\
11 \cdot 3 \pm 0 \cdot 5 \\
11 \cdot 1 \pm 1 \cdot 1\end{array}$ & $\begin{array}{l}12 \cdot 6 \pm 1 \cdot 1 \\
11 \cdot 0 \pm 0.4 \\
10.8 \pm 0.7\end{array}$ & \\
\hline $\begin{array}{l}\text { Anterior myocardial } \\
\text { infarction } \\
\text { Inferior myocardial }\end{array}$ & $11 \cdot 1 \pm 0.8$ & $12 \cdot 0 \pm 0.8$ & \\
\hline infarction & $9.4 \pm 0.7$ & $10.5 \pm 0.7$ & \\
\hline
\end{tabular}

${ }^{\star}$ In the remaining patients $p>0.2$. 
Table 2 Mean number ( $\pm S E M)$ of analgesic injections given in different subgroups. Figures in parentheses are numbers of patients.

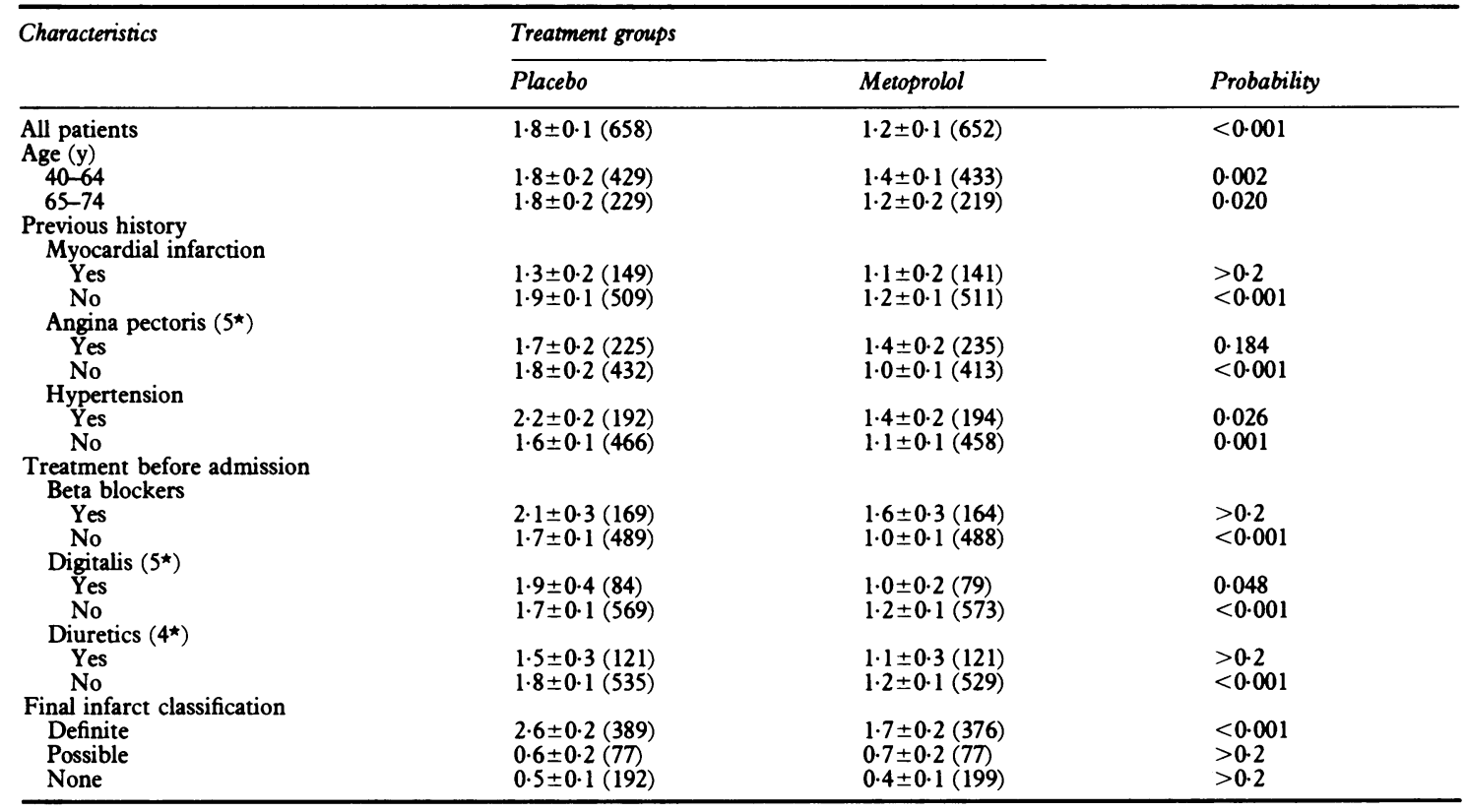

^No of patients for whom data are missing.

secondary endpoint after the first 300 patients had been included and was thereafter recorded prospectively.

\section{STATISTICAL METHODS}

Fisher's permutation test was used. The set of possible hypotheses in this study were not all preconstructed in the protocol. Because of the large number of $p$ values calculated here, the problem of multiple significance tests must be taken into account. A formal significance level is therefore not stated. A crude rule is that the number of hypotheses tested multiplied by the significance level gives an idea of the possible number of falsely declared significances. A reasonable, but informal way, is to take into account other supporting or contradictory results for the final judgment. A two tail test was used. Results are expressed as mean \pm SEM.

\section{Results}

Of the 1395 patients, 809 developed definite myocardial infarction, 162 possible myocardial infarction, while 424 patients did not develop myocardial infarction during the first three days after randomisation. A total of 346 patients had anterior myocardial infarction and 302 inferior myocardial infarction. The mean times from the onset of pain to blind treatment in the different groups are shown in Table 1.

\section{ALL PATIENTS}

In the 1310 patients for whom the number of analgesic injections given was recorded a lower mean number $( \pm$ SEM $)$ of doses was given during the first four days after randomisation in the group treated with metoprolol $(1 \cdot 2 \pm 0 \cdot 1$ analgesic injections $)$ than in those given a placebo $(1.8 \pm 0.1 ; \mathrm{p}<0.001$; Table 2 , Fig. 1).

During the time from admission to hospital to the start of blind treatment a similar number of analgesic injections was given to both groups (metoprolol $1 \cdot 1 \pm 0 \cdot 1$, placebo $1 \cdot 2 \pm 0 \cdot 1 ; p>0 \cdot 2$ ). Among those who were given $\geqslant 10 \mathrm{mg}$ morphine before randomisation the mean number $( \pm$ SEM) of analgesic injections after randomisation was $2.4 \pm 0.2$ in the metoprolol group compared with $3 \cdot 2 \pm 0 \cdot 3$ in the placebo group $(p=0.034)$. A similar reduction in the duration of pain after randomisation was seen (metoprolol $8.9 \pm 0.8 \mathrm{~h}$, placebo $13.4 \pm 1.0 \mathrm{~h} ; \mathrm{p}<0.001$; Fig. 2). The total duration of pain (the time from the onset of pain to the time when the last analgesic dose was given) was also shorter in the metoprolol group than in the placebo group ( $<<0.002)$.

\section{SUBGROUPS}

Delay from onset of pain to inclusion-A similar reduction in the need for analgesics after metoprolol treatment was found in patients included $>12 \mathrm{~h}$ and $\leqslant 12 \mathrm{~h}$ after the onset of pain (Fig. 1). The reduction in the 

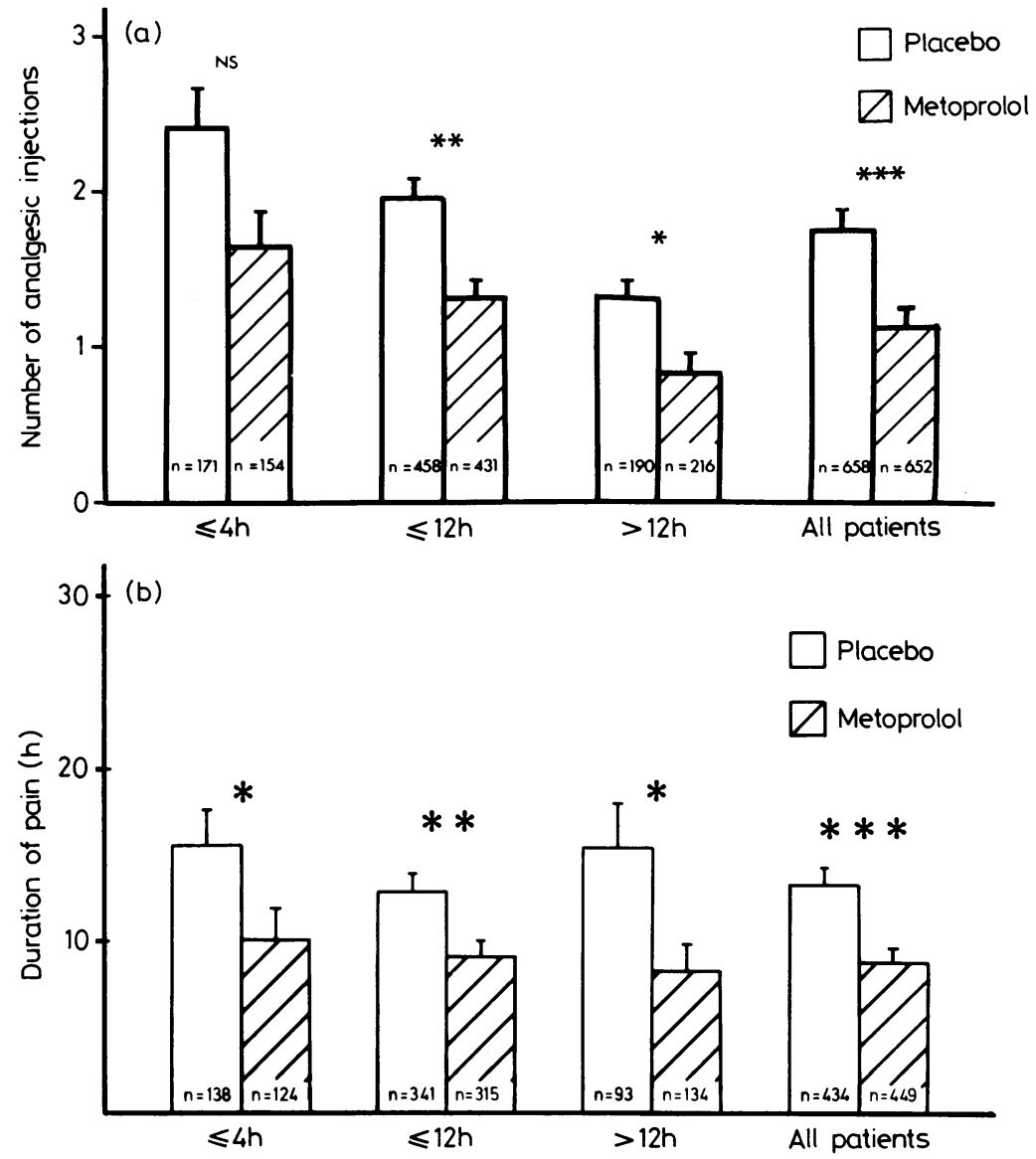

Fig. 1 (a) Number of analgesic injections given during the first four days after inclusion in the study and (b) the duration of pain in all patients and in subgroups in relation to the time from the onset of pain to the start of treatment: $>12 \mathrm{~h}$, more than 12 hours after the onset of pain, $\leqslant 12 \mathrm{~h}$, within 12 hours; $\leqslant 4 \mathrm{~h}$, within four hours. Data on time from the onset of pain

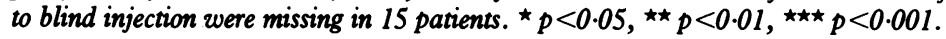

duration of pain was also similar in patients in whom treatment was started $>12 \mathrm{~h}$ and in those treated $\leqslant 12$ $\mathrm{h}$ and $\leqslant 4 \mathrm{~h}$ after the onset of pain (Fig. 1).

Heart rate before inclusion-As can be seen in Fig. 2 the difference in the number of analgesics given as well as the duration of pain seemed to be restricted to patients with an initial heart rate $>60$ beats $/ \mathrm{min}$. In patients with an initial heart rate between 60 and 80 beats/min the mean number of analgesic injections in the metoprolol group was $1 \cdot 2 \pm 0 \cdot 1$ compared with $1.8 \pm 0.2$ in the placebo group $(p=0.005)$. In those with an initial heart rate $>80$ beats/min the mean number of analgesics given in the metoprolol group was $1 \cdot 2 \pm 0 \cdot 2$ compared with $2 \cdot 2 \pm 0.3$ in the placebo group $(\mathrm{p}=0.001)$. There was not, however, any ten- dency to a negative effect of metoprolol in patients with a slow heart rate.

Systolic blood pressure before inclusion-As shown in Fig. 2, the effect on chest pain was found only in patients with initial systolic blood pressures $>120 \mathrm{~mm}$ $\mathrm{Hg}$. Among those with initial systolic blood pressures between 120 and $160 \mathrm{~mm} \mathrm{Hg}$, the mean number of analgesics in the metoprolol group was $1 \cdot 1 \pm 0.2 \mathrm{com}$ pared with $1.5 \pm 0.1$ in the placebo group ( $p=0.007$ ). In those with initial systolic blood pressures $>160$ $\mathrm{mm} \mathrm{Hg}$, the mean number of analgesics given in the metoprolol group was $1 \cdot 2 \pm 0.2$ compared with $2.8 \pm 0.4$ in the placebo group $(\mathrm{p}<0.001)$, and in those with systolic pressures $<120 \mathrm{mmHg}$ there was a slight tendency to longer duration of pain in the 

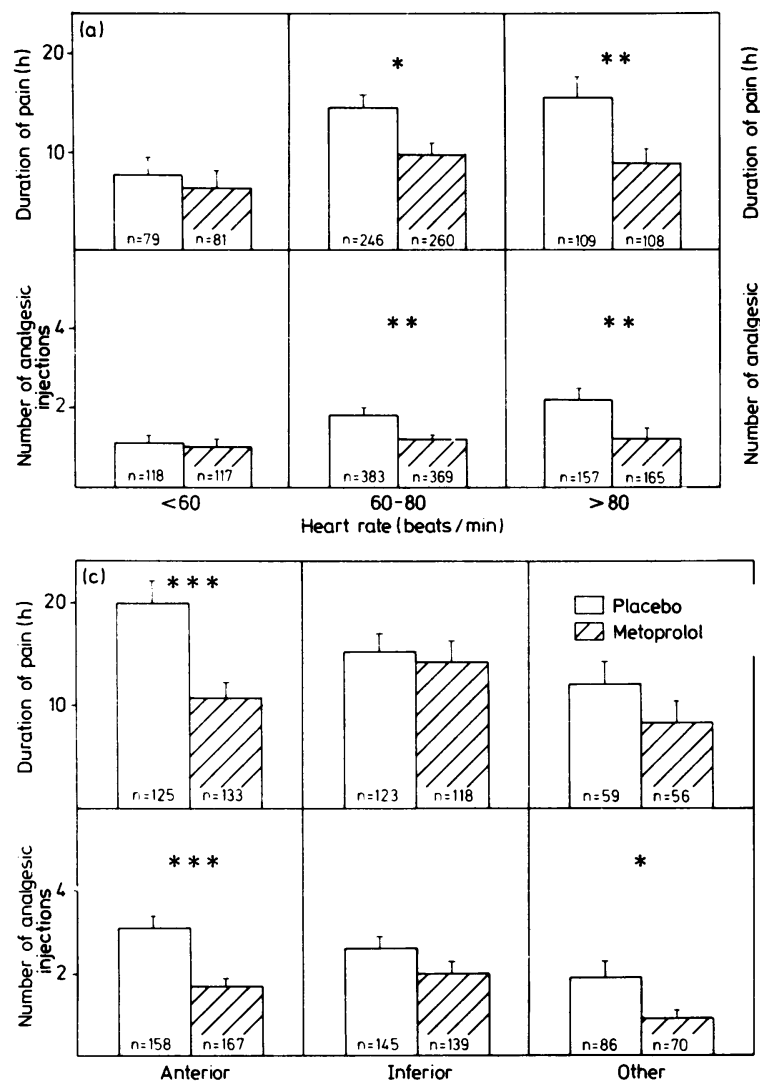

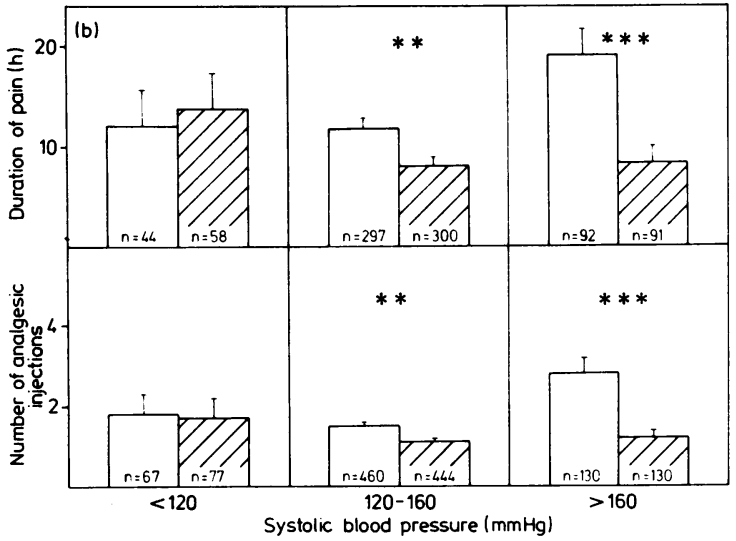

Fig. 2 Duration of pain and the number of analgesic injections given $(a)$ in relation to heart rate immediately before the start of treatment; $(b)$ in relation to systolic blood pressure immediately before the start of treatment; and $(c)$ in relation to the electrocardiographically determined site of infarction in patients with definite myocardial infarction. ${ }^{\star} p<0.05,{ }^{\star} p<0.01$, $\star \star \star p<0.001$. metoprolol group but no difference with respect to the number of analgesic injections given.

Electrocardiographically determined infarct size-The difference in the number of analgesics given as well as the duration of pain was most pronounced in patients with anterior myocardial infarction and other myocardial infarction but less pronounced in inferior myocardial infarction (Fig. 2). The mean number of analgesic injections given in anterior myocardial infarction was $1.7 \pm 0.2$ for the metoprolol group and $3.1 \pm 0.3$ for the placebo group $(p<0.001)$, in other myocardial infarction the mean value for each group was $0.9 \pm 0.2$ (metoprolol) and $1.9 \pm 0.4$ (placebo) $(p=0.035)$; and in inferior myocardial infarction, the mean value for the metoprolol group was $2.0 \pm 0.3$ compared with $2 \cdot 6 \pm 0.3$ in the placebo group $(\mathrm{p}>0 \cdot 2)$.

Table 3 Mean number ( $\pm S E M)$ of analgesic injections given in different subgroups. Figures in parentheses are numbers of patients

\begin{tabular}{|c|c|c|c|}
\hline \multirow[t]{2}{*}{ Characteristics before stant of treatment } & \multicolumn{2}{|l|}{ Treatment group } & \multirow[b]{2}{*}{ Probability } \\
\hline & Placebo & Metoprolol & \\
\hline $\begin{array}{l}\text { Electrocardiographic changes }\left(1^{\star}\right) \\
\text { None } \\
\text { ST-T wave } \\
\text { Q wave } \\
\text { Signs of anterior infarction } \\
\text { Signs of inferior infarction }\end{array}$ & $\begin{array}{l}1 \cdot 1 \pm 0.1(332) \\
2 \cdot 0 \pm 0.3(171) \\
3 \cdot 1 \pm 0.3(154) \\
2 \cdot 5 \pm 0.3(171) \\
2.6 \pm 0.3(126)\end{array}$ & $\begin{array}{l}0.6 \pm 0.1(315) \\
1.5 \pm 0.2(173) \\
1.8 \pm 0.3(164) \\
1.7 \pm 0.2(179) \\
2.0 \pm 0.3(123)\end{array}$ & $\begin{array}{l}0.006 \\
>0.2 \\
0.001 \\
0.013 \\
0.184\end{array}$ \\
\hline $\begin{array}{l}\text { Signs of heart failure }\left(23^{\star}\right) \\
\text { No ausculatatory rales } \\
\text { Auscultatory rales }\end{array}$ & $\begin{array}{l}1.6 \pm 0.1(586) \\
2.8 \pm 0.5(60)\end{array}$ & $\begin{array}{l}1 \cdot 0 \pm 0.1(567) \\
2.2 \pm 0.4(74)\end{array}$ & $\begin{array}{l}<0.001 \\
>0.2\end{array}$ \\
\hline
\end{tabular}

$\star$ No of patients for whom data are missing. 


\section{FURTHER SUBGROUP ANALYSIS}

Several subgroups were analysed according to age, history, final diagnosis, and clinical findings at entry. As can be seen in Tables 2 and 3, in all these subgroups except one (patients with possible infarctions), fewer analgesic injections were given to the metoprolol group than to the placebo group.

\section{Discussion}

Chest pain is a major symptom in acute myocardial infarction and is thought to reflect the severity of ischaemia or infarct development. Apart from conventional analgesics such as morphine and its equivalents, interventions with different drugs have been shown to relieve pain in myocardial infarction. Martins de Oliviera et al showed in 1959 that hyaluronidase given intravenously in patients with acute myocardial infarction resulted in relief of pain and reduction of the ST elevation. ${ }^{11}$ Treatment with beta blockers relieves pain in angina pectoris. ${ }^{2}{ }^{3}$ It has been suggested that improvement of the imbalance between oxygen supply and oxygen demand would be useful in myocardial infarction as well as in angina pectoris. ${ }^{12}$ In several pilot studies in man, the intravenous administration of beta blockers to patients with myocardial infarction has also caused the relief of chest pain. ${ }^{4-6}$ Favourable metabolic responses, such as decreased lactate production after treatment with propranolol in patients with myocardial infarction, have also been reported. ${ }^{13}$ These effects may reflect an anti-ischaemic effect of beta blockade in myocardial infarction. This is supported by a reduction of the ST elevation ${ }^{4}$ and a limitation of the enzymatically and electrocardiographically estimated infarct size after early beta blockade in myocardial infarction. ${ }^{14-16}$

In the present study, a smaller number of analgesic injections was given and a shorter duration of pain was seen in patients treated with metoprolol than in those given a placebo regardless of the delay from the onset of pain to the start of treatment. From these results, which are in agreement with previous studies, it seems that if beta blockers are given to patients with suspected acute myocardial infarction fewer problems of chest pain will appear during the following days.

Several subgroups were analysed retrospectively, and they indicated that some factors could be of importance in the pain relieving effect. Patients with a lower initial heart rate and systolic blood pressure did not seem to react as favourably as the other patients. Furthermore, a less pronounced effect was seen in patients with inferior myocardial infarction than in patients with anterior or other myocardial infarction. These results are in agreement with the theory that patients with a higher initial sympathetic tone or without a raised parasympathetic tone will have more substantial pain relief after beta blockade.

The methods used for evaluating chest pain could be criticised for being inadequate. Narcotic analgesia (morphine) was the only principle treatment for severe chest pain in the acute phase of myocardial infarction. Other drugs, such as intravenous glyceryl trinitrate or intravenous nitroprusside, were not given. A close correlation has been observed between the patients' own scoring of pain and the amount of analgesics given (unpublished data). Furthermore, the doctors were not aware of how the patients reacted to the blind treatment.

There are several possible explanations for the mechanisms behind the pain relieving effect of beta blockade in myocardial infarction. No analgesic effect has been shown. Limitation of the infarct size might result in pain relief. Indeed, a correlation was seen between both the number of analgesic injections given and the estimated duration of pain and the indirect signs of the infarct size (to be published). An antiischaemic effect, not always related to infarct limitation, and a reduction of the rate-pressure product ${ }^{17}$ are other possible mechanisms. Decreased contractility might also reduce pain because of lowered oxygen consumption.

The number of analgesic injections given and the estimated duration of pain are two clinical variables that may be evaluated to obtain more information on whether different types of interventions in acute myocardial infarction are beneficial.

This study was supported by grants from the Swedish Medical Research Council, the Swedish National Association against Heart and Chest Diseases, the Göteborg Medical Society, and AB Hässle, subsidiary of Astra Pharmaceuticals, Sweden.

\section{References}

1 Gianelly RE, Goldman RH, Treister B, Harrison DC. Propranolol in patients with angina pectoris. Ann Intern Med 1967; 67: 1216-25.

2 Keyriläinen O, Uusitalo A. Effects of metoprolol in angina pectoris. A subacute study with exercise tests and a long-term tolerability study. Acta Med Scand 1976; 199: 491-7.

3 Thadani U, Davidson C, Chir B, Singleton W, Taylor SH. Comparison of the immediate effects of five $\beta$-adrenoreceptor-blocking drugs with different anticillary properties in angina pectoris. $N$ Engl $\mathcal{f}$ Med 1979; 300: 750-5.

4 Waagstein F, Hjalmarson A. Double-blind study of the effect of cardioselective beta-blockade on chest pain in acute myocardial infarction. Acta Med Scand 1975; (suppl 587): 201-8. 
5 Gold HK, Leinbach RC, Maroko PR. Propranololinduced reduction of signs of ischemic injury during acute myocardial infarction. Am f Cardiol 1976; 38: 689-95.

6 Jugdutt BI, Lee SJK. Intravenous therapy with propranolol in acute myocardial infarction. Chest 1978; 74: 514-21.

7 Ramsdale DR, Faragher EB, Bennett DH, et al. Ischemic pain relief in patients with acute myocardial infarction by intravenous atenolol. Am Heart $\mathcal{F}$ 1982; 103: $459-67$

8 Hjalmarson $\AA$, Elmfeldt D, Herlitz J, et al. Effect on mortality of metoprolol in acute myocardial infarction. Lancet 1981; ii: 823-7.

9 Scandinavian Committee on Enzymes. Recommended method for determination of four enzymes in blood. Scand f Clin Lab Invest 1974; 33: 291-306.

10 Brydon WG, Smith AF. An appraisal of routine methods for the determination of the anodal isoenzymes of lactate dehydrogenase. Clin Chim Acta 1973; 43: 361-9.

11 Martins de Oliveira J, Carballo R, Zimmerman HA. Intravenous injection of hyaluronidase in acute myocar- dial infarction: preliminary report of clinical and experimental observations. Am Heart $\mathcal{f}$ 1959; 57: 712-22.

12 Maroko PR, Kjekshus JK, Sobel BE, et al. Factors influencing infarct size following experimental coronary artery occlusions. Circulation 1971; 43: 67-82.

13 Mueller HS, Ayres SM, Religa A, Evans RG. Propranolol in the treatment of acute myocardial infarction. Circulation 1974; 49: 1078-87.

14 Peter T, Norris RM, Clarke ED, et al. Reduction of enzyme levels by propranolol after acute myocardial infarction. Circulation 1978; 57: 1091-5.

15 Yusuf S, Peto R, Bennett D, et al. Early intravenous atenolol treatment in suspected acute myocardial infarction. Lancet 1980; ii: 273-6.

16 Herlitz J, Elmfeldt D, Hjalmarson $\AA$, et al. Effect of metoprolol on indirect signs of the size and severity of acute myocardial infarction. Am $\mathcal{f}$ Cardiol 1983; 51: 1282-8.

17 Málek I, Waagstein F, Hjalmarson $\AA$, Holmberg S, Swedberg K. Hemodynamic effects of the cardioselective $\beta$-blocking agent metoprolol in acute myocardial infarction. Acta Med Scand 1978; 204: 195-201. 